\title{
Intraoperative transesophageal echocardiogram evaluation for liver transplantation
}

\author{
Marta Ines Berrio Valencia and Abigayel Joschko \\ Department of Anesthesiology, Western University - London Health Sciences Centre, London, ON, Canada
}

Transesophageal echocardiography (TEE) is a powerful tool for diagnosis and management in both cardiac and noncardiac surgeries. TEE is especially relevant during liver transplantation as patients often have underlying cardiac or pulmonary diseases, large volume shifts are anticipated, and patients are prone to thrombotic complications. The American Society of Echocardiography Guidelines assigned a grade B2 to TEE as a hemodynamic monitoring tool in this context [1].

We present a TEE protocol developed at London Health Science Centre for use during liver transplantation (Table 1) based on recent literature [2-5]. This protocol includes a comprehensive baseline examination during the dissection phase, followed by a more focused assessment during the anhepatic and neohepatic phases. We emphasize the importance of labeling the TEE loops during the different phases for quality of reporting, as well as for education and research purposes. During the anhepatic phase, we limit TEE probe manipulation and focus predominantly on midesophageal views. During the neohepatic phase, we aim for windows through the inferior vena cava and perform hepatic vein evaluation if the quality of the images permits. Although these views are not yet standardized in liver transplantation, there is increasing interest in the literature in this regard, and we try to include them as part of our global evaluation.

Corresponding author: Marta Ines Berrio Valencia, M.D., MSc Department of Anesthesiology, Western University - London Health Sciences Centre, 339 Windermere Road, London, ON N6A 5A5, Canada

Tel: +1-519-2822816

Email: martaberrio@gmail.com

ORCID: https://orcid.org/0000-0003-0975-7360

Received: November 27, 2018.

Revised: December 5, 2018 (1st); January 15, 2019 (2nd).

Accepted: January 16, 2019.

Korean J Anesthesiol 2019 August 72(4): 385-386

https://doi.org/10.4097/kja.d.18.00331
Table 1. Protocol for Transesophageal Echocardiogram in Liver Transplantation

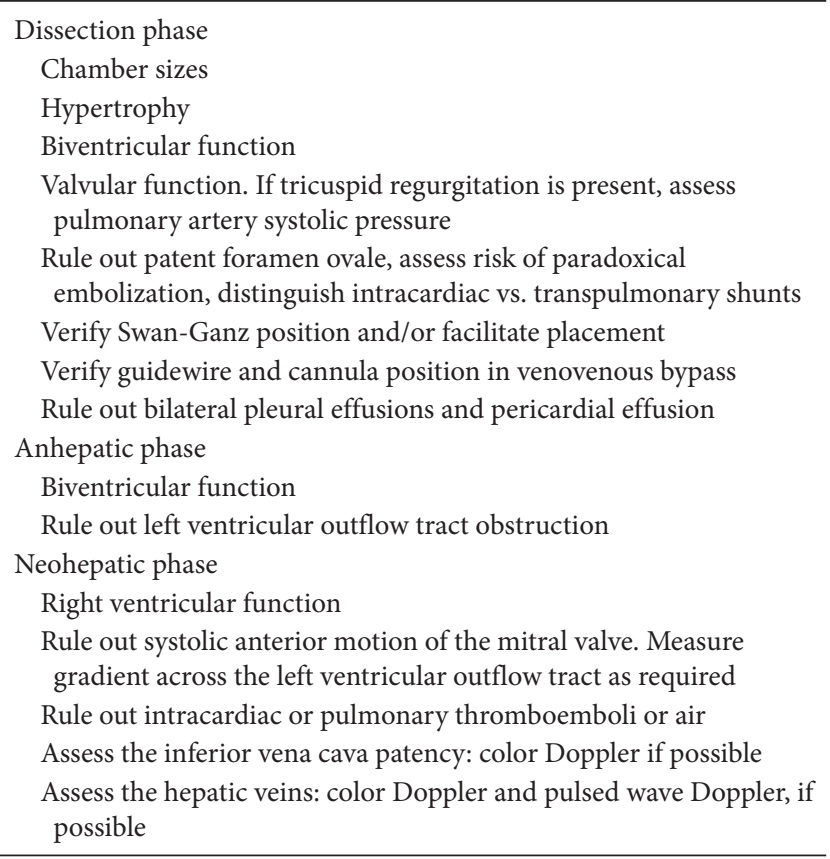

We hope to see more literature regarding TEE during liver transplantation and the development of focused guidelines for use of TEE as a perioperative tool for the transplant anesthesiologist.

\section{Conflicts of Interest}

No potential conflict of interest relevant to this article was reported.

\section{Author Contributions}

Marta Ines Berrio Valencia (Writing - original draft; Writing -

(c) This is an open-access article distributed under the terms of the Creative Commons Attribution Non-Commercial License (http://creativecommons.org/ licenses/by-nc/4.0/), which permits unrestricted non-commercial use, distribution, and reproduction in any medium, provided the original work is properly cited. 
review \& editing)

Abigayel Joschko (Writing - original draft; Writing - review \& editing)

\section{ORCID}

Marta Ines Berrio Valencia, https://orcid.org/0000-0003-0975-7360 Abigayel Joschko, https://orcid.org/0000-0002-2941-0981

\section{References}

1. Porter TR, Shillcutt SK, Adams MS, Desjardins G, Glas KE, Olson JJ, et al. Guidelines for the use of echocardiography as a monitor for therapeutic intervention in adults: a report from the American Society of Echocardiography. J Am Soc Echocardiogr 2015; 28 : 40-56.

2. Vetrugno L, Barbariol F, Baccarani U, Forfori F, Volpicelli G, Della Rocca G. Transesophageal echocardiography in orthotopic liver transplantation: a comprehensive intraoperative monitoring tool. Crit Ultrasound J 2017; 9: 15.

3. Dalia AA, Flores A, Chitilian H, Fitzsimons MG. A comprehensive review of transesophageal echocardiography during orthotopic liver transplantation. J Cardiothorac Vasc Anesth 2018; 32: 1815-24.

4. Vetrugno L, Barnariol F, Bignami E, Centonze GD, De Flaviis A, Piccioni F, et al. Transesophageal ultrasonography during orthotopic liver transplantation: show me more. Echocardiography 2018; 35: 1204-15.

5. Roscoe A, Fayad A, Carrier F, Denault A. Echocardiography in non-cardiac procedures and trauma. In: Basic Transesophageal and Critical Care Ultrasound. Edited by Denault A, Vegas A, Lamarche Y, Tardif JC, Couture P: Florida, CRC Press. 2018, pp 217-20. 